\title{
Argentine Patagonia barberry chemical composition and evaluation of its antioxidant capacity
}

\author{
Patricia Boeri $^{1,2}$ | Lucrecia Piñuel $^{1,2}$ | Daniela Dalzotto ${ }^{1}$ | Romina Monasterio ${ }^{3}$ | \\ Ariel Fontana $^{3}$ | Sandra Sharry ${ }^{1,4}$ | Daniel Alejandro Barrio ${ }^{1,2}$ | Wilman Carrillo ${ }^{5}$
}

${ }^{1}$ Universidad Nacional de Rio Negro, Rio Negro Viedma, Argentina

${ }^{2}$ CIT-Rio Negro -CONICET, Viedma, Río Negro, Argentina

${ }^{3}$ Institute of Agricultural Biology of Mendoza (IBAM), UNCuyo-CONICET, Mendoza, Argentina

${ }^{4}$ Wood Research Laboratory (LIMAD), Faculty of Agricultural and Forestry Sciences, National University of La Plata, La Plata, Argentina

${ }^{5}$ Faculty of Agricultural Sciences, Technical University of Babahoyo, Babahoyo, Ecuador

\section{Correspondence}

Wilman Carrillo, Faculty of Agricultural Sciences, Technical University of Babahoyo, Av. Universitaria Km 21/2 Av. Montalvo, Babahoyo CP 120301, Ecuador. Email:wi.carrillo@uta.edu.ec,wcarrillo@utb. edu.ec

\begin{abstract}
An important portion of vitamins, minerals and polyphenols components in human diet are captured from fruit consumption. Argentinean Patagonia Berberis microphylla was characterized with the phenolic content, the proximate composition and the identification and quantification of anthocyanins, not-anthocyanins and proteins. The antioxidant capacity of berberis ethanolic extracts (EB) was determined by the 2,2'-azino-bis(3-ethylbenzothiazoline-6-sulfonic acid) (ABTS) and 2,2-diphenyl-1picrylhydrazyl (DPPH) assays. EB was used to reduce production of reactive substances species (ROS) in zebrafish. EB presented a total polyphenols content of $1,035.03 \mathrm{mg}$ $\mathrm{GAE} / 100 \mathrm{~g}$ fresh weight (FW). EB presented an ABTS value of $116.25 \pm 17 \mu \mathrm{mol}$ TE/g FW. EB presented a DPPH value of $137.80 \pm 1.90 \mu \mathrm{mol}$ TE/g FW. EB was able of reducing the ROS in zebrafish. Berberies Protein Isolate (BPI) presented proteins with bands from 15 to $62 \mathrm{kDa}$. BPI presented an ABTS value of $593.11 \pm 8.60 \mu \mathrm{mol} \mathrm{TE} / \mathrm{g}$. The BPI duodenal digest presented a value of $641.07 \pm 12.60 \mu \mathrm{mol} T E / g$ digests.

\section{Practical applications}

The practical applications of the present study are to increase scientific knowledge for consumers about the quality and benefits of the consumption of the native fruit (Berberis microphylla) from the Patagonia region of Argentine. This work describes the protein profile of berberies, their digestibility and their antioxidant activity. This study allows to better understand the phytonutrients that make up this fruit. Future studies may identify the peptides present in hydrolyzates. The bio-compounds of this fruit

could be used as functional ingredients by the food industry for different purposes.
\end{abstract}

\section{KEYWORDS}

antioxidant activity, Berberis microphylla, calafate barberry, total polyphenols content, zebrafish

\section{1 | INTRODUCTION}

Polyphenols bioactive compounds are phytochemical components that have been widely studied for their benefits on human health.

Patricia Boeri and Lucrecia Piñuel contributed equally to the work.
Many epidemiological studies have been described in the literature on the protective effect of diets based on components of plant origin (Speisky, López-Alarcón, Gómez, Fuentes, \& Sandoval-Acuña, 2012). These diets are rich in polyphenol and prevention of diseases such as cancer, coronary heart, oxidative-stress-related diseases, and osteoporosis (Kampa, Nifli, Notas, \& Castanas, 2007; 
Pennington \& Fisher, 2010). The results of these studies have raised interest in the polyphenols research and its antioxidant capacity to scavenge reactive oxygen species (ROS). Studies have reported that ROS may be related to different degenerative diseases such as cancer, respiratory diseases, Alzheimer. Antioxidants as a nutritional supplement have shown being essential for ROS neutralization of associated oxidative damages (Liu et al., 2018). In recent years, Patagonia fruits have been the subject of several investigations describing their antioxidant potential and their potential benefits on human health (Afrin et al., 2016; Fuentes, Figueroa, Valdenegro, $\&$ Vinet, 2019). Blueberries among other fruits have gained popularity and significant attention. They have been denominated "superfruits" as a term to promote the health benefits of these fruits. The superfruits are considered "super" by nutrition scientists when fruits have extremely high levels of antioxidants, fibers, vitamins, minerals, and other nutrients that improve health (Chang, Alasalvar, \& Shahidi, 2019).

Calafate barberry (Berberis microphylla G. Forst, sin.) is an endemic species of the Patagonian Andes of Argentina and Chile, with a potential use for agroindustry. Although the phytochemical and ethnopharmacological analysis of the medicinal Argentine flora has been described in the literature (Barboza, Cantero, Núñez, Ariza-Espinar, \& Pacciaroni, 2009), native berries such as calafate have not been deeply studied. The B. microphylla fruits produce small dark berries with great edible value and are considered superfruits due to their vitamin $\mathrm{C}$ high content and their polyphenols levels. The polyphenols levels are higher than levels registered in other berries (López de Dicastillo, López-Carballo, Gavara, Muriel Galet, Guarda, \& Galotto, 2019; Ramirez, Zambrano, Sepulveda, Kennelly, \& Simirgiotis, 2015; Rothwell et al., 2016). The fruits have a high antioxidant capacity demonstrated by different traditional quantitative in vitro methods (Ruiz et al., 2010, 2013, 2014). Environmental conditions during fruit growth influence the synthesis of fruit polyphenols compounds and the antioxidant capacity (Arena, Postemsky, \& Curvetto, 2017. Roussos, Denaxa, $\&$ Damvakaris, 2009). The main objective of this research was to evaluate the chemical composition of the B. microphylla fruit pulp and its seeds and, finally, to evaluate the antioxidant capacity of polyphenols components and proteins.

\section{2 | MATERIALS AND METHODS}

\section{1 | Reactive}

Folin-Ciocalteu reactive, 2,2-diphenyl-1-picrylhydrazyl (DPPH), gallic acid standard, 2,2'-azino-bis(3-ethylbenzothiazoline-6sulfonic acid) (ABTS) 6-hydroxy-2,5,7,8-tetramethylchroman-2carboxylic acid (trolox reactive), 2,2'-Azobis(2-amidinopropane) dihydrochloride (AAPH), Dichloro-dihydro-fluorescein diacetate (DCFH-DA) were obtained from Sigma Chemical Co. (St Louis, MO, USA).

\section{2 | Standards of non-anthocyanins and anthocyanins compounds}

The next standards were used to identify and quantify the phenolic compounds:

Gallic acid, 3-hydroxytyrosol, (-) gallocatechin, (-) gallocatechin gallate, $(-)$ epicatechin gallate, procyanidin $\mathrm{B} 1,(+)$ catechin, procyanidin B2, (-) epicatechin, caffeic acid, syringic acid, coumaric acid, ferulic acid, trans-resveratrol, quercetin hydrate, kaempferol-3-glucoside, and malvidin-3-O-glucoside chloride with values of purity between $90 \%$ and $99.5 \%$.

All compounds were obtained of Sigma-Aldrich (Sigma-Aldrich, St. Louis, MO, USA). The standard of 2-(4-hydroxyphenyl) ethanol (tyrosol) with $99.5 \%$ of purity was obtained from the company Fluka (Buchs, Switzerland).

\section{3 | Samples}

Berberis fruits (B. microphylla) from 20 different trees were harvested in February 2017 and February 2018 in the extra-Andean

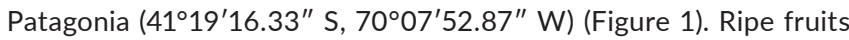
were quickly processed to facilitate the seeds manual separation. The pulp was frozen at $-20^{\circ} \mathrm{C}$ until further analysis.

\section{4 | Polyphenol extraction from B. microphylla fruit}

The extracts from berberis (EB) were obtained by the solid-liquid extraction method. Briefly, $10 \mathrm{~g}$ of berberis pulp was mixed with a volume of the extraction solvent (ethanol: water, 50:50 v/v) at a ratio of $25: 1$, solvent: sample. EB was isolated during $2 \mathrm{hr}$ at $60^{\circ} \mathrm{C}$. EB was lyophilized and kept at $-20^{\circ} \mathrm{C}$. EB dry content was calculated by Iyophilization in triplicate. Yields were expressed as $\mathrm{g}$ of EB/100 g of berberis pulp (DW).

\section{5 | Nutritional characterization of fresh fruit pulp}

The proximate analysis of berberis was made using the standard protocols of the Association of Official Analytical Chemists (AOAC, 1990). Total polysaccharides were determined using the phenol sulfuric acid method. The content of total soluble reduced sugars was calculated by the Somogyi-Nelson method. The results calculated were expressed as g of glucose/100 g (DW).

\subsection{Total polyphenols content (TPC)}

The EB total soluble polyphenols components was determined by the Folin-Ciocalteu (FC) method using the gallic acid standard. The assays were performed in triplicate, and the date calculated were 

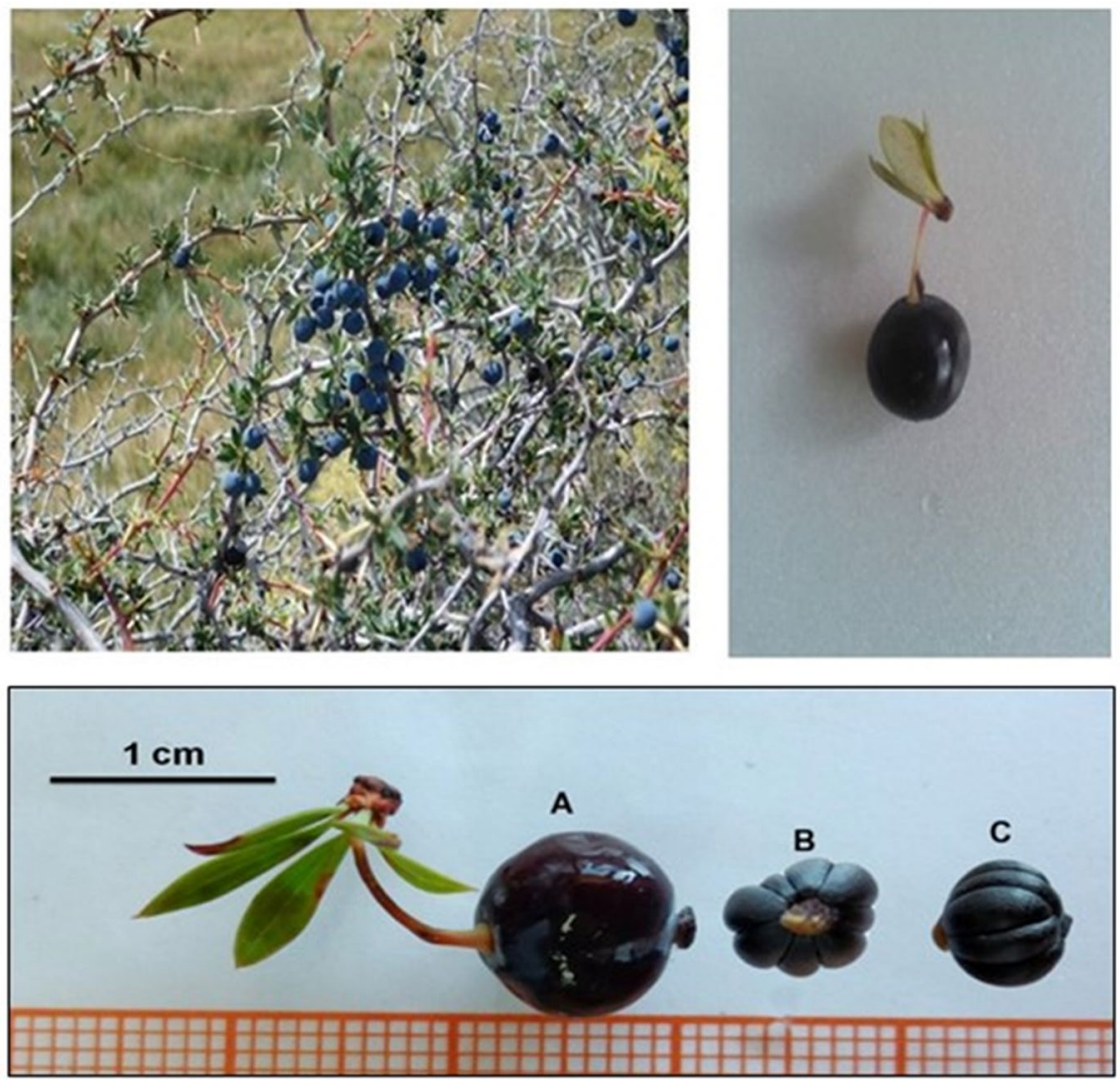

FIGURE 1 Patagonia Argentina Berries. Calafate barberry (Berberis microphylla G. Forst, sin.). The top photograph is a Calafate bush. Size ratio $(\mathrm{cm})$ of the whole fruit $(A)$ of $B$. microphylla compared to the seeds, seen from above $(B)$ and from the side (C)

presented as mg gallic acid equivalent (GAE)/g of EB. The standard curve obtained was $\left(Y=0.197 x+0.0442, R^{2}=0.994\right)$.

\section{7 | Determination polyphenols components}

Non-anthocyanins and anthocyanins components were analyzed by the HPLC-DAD technique according to Fontana, Antoniolli, Fernández, and Bottini (2017). HPLC separation was made using a Dionex Ultimate 3000 HPLC-DAD system (Dionex Softron GmbH, Thermo Fisher Scientific Inc., Germering, Germany) and a Kinetex C18 column (3.0 × 100 mm, $2.6 \mathrm{~mm}$ ) (Phenomenex, Torrance, CA, USA). The conditions of analysis to non-anthocyanins component was as solvent A (Milli-Q- water $+0.1 \%$ of formic acid) and as solvent $B$ (acetonitrile). The analysis was made with a gradient of 0-14 min with $95 \%$ of solvent B; $14-15.5$ min with $95 \%$ of solvent $B ; 15.5-17$ min with $5 \%$ of solvent $B$. The measurements were made at wavelengths of 254, 280, 320 and $370 \mathrm{~nm}$. The conditions of analysis of anthocyanins components were as solvent A (Milli-Q water: formic acid: acetonitrile, 87:10:3, v:v:v), as solvent B (Milli-Q water: formic acid: acetonitrile, 40:10:50, v:v:v). The analysis was made using a gradient of $0-15 \mathrm{~min}, 100 \%$ of solvent $\mathrm{B} ; 15-17 \mathrm{~min}$, $10 \%$ of solvent $B$. The measurement was taken at wavelengths of $520 \mathrm{~nm}$

\section{8 | In vitro antioxidant activity}

EB antioxidant capacity was calculated by the DPPH and ABTS assays. Trolox reactive was used as standard with concentrations of $0-0.95 \mathrm{mM}$ of calibration curve $\left(Y=0.2808 x+0.3552 ; R^{2}=0.998\right)$. Antioxidant capacity was calculated as $\%$ of activity $=($ Absorbance of control - Absorbance of sample/Absorbance of control) $\times 100$. Also, the samples IC50 was calculated and expressed as the concentration of the sample necessary to inhibit $50 \%$ of free radicals (Piñuel, Vilcacundo, et al., 2019).

\subsection{In vivo antioxidant activity assay with the zebrafish embryos model}

\subsection{1 | Exposure of embryos of zebrafish to phenolic extracts and AAPH}

Zebrafish embryos of 4-6-hr post-fecundation (hpf) ( $n=8$ ) were put in wells of 24 -well sterile plates in $500 \mu$ of media with $0.1 \%$ DMSO. The EB sample was added to the wells at concentrations of 0,5 and $10 \mu \mathrm{g} / \mathrm{ml}$ with $0.1 \%$ DMSO. Zebrafish embryos were incubated with the samples for $2 \mathrm{hr}$. After incubation $500 \mu \mathrm{l}$ of $25 \mathrm{mM}$ of AAPH solution was added in each well and was incubated for $4 \mathrm{hr}$ at $28^{\circ} \mathrm{C}$. 
Then, zebrafish embryos were rinsed using fresh embryo media until $24 \mathrm{hpf}$ were completed. The assay was performed in triplicate ( $\mathrm{Hu}$ et al., 2017; Vilcacundo et al., 2018).

\subsection{0 | Measurement of stress-induced oxidative intracellular ROS generation}

Zebrafish embryos model was used to evaluate the formation of ROS in the cells. The DCFH-DA fluorescent assay was used to quantify ROS in zebrafish embryos. Zebrafish embryos of one day post-fecundation (dpf) were treated with a DCFH-DA reactive $(2.0 \mu \mathrm{l} / \mathrm{ml})$ for $1 \mathrm{hr}$ at $28.5 \pm 1^{\circ} \mathrm{C}$, protected from light. Then, zebrafish embryos were rinsed by fresh embryo media, dechorionated, anesthetized before observation, and photographed under the microscope (Leica DM1000 LED, Wetzlar, Germany) with a camera Moticam 2000 (Taiwan, China). ROS generation percentage of zebrafish embryos was calculated using the image J program (Piñuel, Boeri, et al., 2019; Yang et al., 2012).

\subsection{1 | Nutritional characterization of seeds fruit}

For the proximal analysis the determination of the moisture content, total proteins, lipids and ashes of both pulp and seeds was carried out with the protocol recommended by the Association of Official Analytical Chemists (AOAC, 1990).

\subsection{2 | Fresh weight and dry weight}

To determine the moisture content, $20 \mathrm{~g}$ of seed flour were disposed. The humidity was determined by weight difference before and after drying the sample at $75^{\circ} \mathrm{C}$, until constant weight was reached.

\subsection{3 | Ashes}

The ashes were obtained by mineralization of the dehydrated samples, at a temperature of $550^{\circ} \mathrm{C}$ for $12 \mathrm{hr}$ in muffle (TecnoEdu S.A).

\subsection{4 | Total protein}

Calafate seeds protein content was calculated by the Kjeldhal method (AOAC, 1990) in duplicate. The protein calculation was made from the nitrogen data obtained from the sample, using the 6.25 conversion factor.

\subsection{5 | Lipids}

Lipid extraction was performed from $5 \mathrm{~g}$ of seed and $5 \mathrm{~g}$ of pulp, with two repetitions of each. The Soxhlet method was made with sulfuric ether as solvent. The extraction of the fats was made for $2 \mathrm{hr}$. The percentage of lipids was obtained by the difference between the final and initial weight of the ball (Lanzi et al., 2018).

\subsection{6 | Berberies protein isolate (BPI)}

The seeds were used to obtain flour. The seeds were dried for $24 \mathrm{hr}$ at $28^{\circ} \mathrm{C}$. An alkaline extraction followed using the isoelectric precipitation method was made according to Acosta, Carpio, Vilcacundo, and Carrillo (2016) with some modifications. About $3 \mathrm{~g}$ of flour were mixed with $30 \mathrm{ml}$ of distilled water and $\mathrm{pH}$ was adjusted at 9.0. Then, the sample was centrifuged at 5,000 rpm, and the pellet was discarded. The $\mathrm{pH}$ of the supernatant was adjusted to $\mathrm{pH}$ 5.0. Finally, the sample was centrifuged at 5,000 rpm and the precipitate was adjusted at $\mathrm{pH}$ 7.0. The aqueous extract obtained was lyophilized to obtain peptides and to carry out the in vitro analysis of the antioxidant activity.

\subsection{7 | Gastrointestinal hydrolysis}

The hydrolyzates were obtained from the BPI by simulating the digestive process with proteases, for which the proteins were hydrolyzed by simulating the gastric and duodenal digestive process as described by Vilcacundo et al. (2018).

\subsection{1 | Gastric digestion}

$10 \mathrm{mg}$ of the lyophilized BPI was used and $1 \mathrm{ml}$ of (pepsin 2,000 U/ $\mathrm{ml}$, at $\mathrm{pH}$ 3.0) was added. The sample was incubated for $120 \mathrm{~min}$ at $37^{\circ} \mathrm{C}$. The hydrolytic activity of the enzymes was stopped by raising the $\mathrm{pH}$ with $100 \mu \mathrm{l}$ of $1 \mathrm{M} \mathrm{NaOH}$ and with a bath at $80^{\circ} \mathrm{C}$ for $10 \mathrm{~min}$.

\subsection{2 | Duodenal digestion}

$1 \mathrm{ml}$ of gastric hydrolysis was mixed with $1 \mathrm{ml}$ of pancreatin solution $(100 \mathrm{U} / \mathrm{ml}$ at $\mathrm{pH} 7.0)$ and incubated for $120 \mathrm{~min}$ at $37^{\circ} \mathrm{C}$. Then, the reaction was terminated with a bath at $80^{\circ} \mathrm{C}$ for $10 \mathrm{~min}$. The $\mathrm{pH}$ was adjusted to $\mathrm{pH}$ 7.0.

\subsection{8 | Physicochemical characterization of $\mathrm{BPI}$ and digests}

For the characterization of the protein isolate, a 12\% SDS-PAGE gel according to Quinteros, Vilcacundo, Carpio, and Carrillo (2016) was used. The polypeptide profile of the protein hydrolyzate was characterized by a $16 \%$ Tricine-SDS-PAGE gel. 


\subsection{Analysis of the in vitro antioxidant activity}

The ability to capture free radicals from the protein isolate, protein hydrolyzate and its fractions was determined. For the measurement of this activity, the DPPH and ABTS methods were used (Piñuel, Boeri, et al., 2019). The reference standard used was $1 \mathrm{mM}$ of Trolox (0-0.95 mM of calibration curve). The standard curve obtained was $\left(Y=0.4939 x+1.2438, R^{2}=0.995\right)$. The IC50 value was calculated. This value was defined as the concentration of the sample necessary to inhibit $50 \%$ of the free radicals for the ABTS method.

\subsection{0 | Cytotoxicity test of BPI in zebrafish eggs}

The wild type zebrafish colony was established in the laboratory of the Universidad Nacional de Rio Negro (UNRN) Viedma, Argentina, in an environmental growth or glass aquarium, provided with a system of filtration and an aerator activated carbon for water oxygenation. Adult zebrafish were kept on $16 \mathrm{hr}$ light and $8 \mathrm{hr}$ dark cycles. Zebrafish embryos were obtained by photoinduced spawning over green plants, and then, cultured at $28^{\circ} \mathrm{C}$ in a fishbowl. Early zebrafish eggs were maintained according to Vilcacundo et al. (2017). Zebrafish eggs post-fecundation were used to the assays. Zebrafish eggs (30 eggs/well) were incubated in 24-well plates. BPI digests were added at different concentrations ( 0 and $0.25 \mathrm{mg} / \mathrm{ml}$ ) in $200 \mu$ l of water. The effect of BPI on zebrafish embryos were analyzed for 4, 12 and $24 \mathrm{hr}$. At the end of the incubation time, zebrafish eggs mortality and morphologic changes were observed, determining the percentage of dead eggs. Stereoscopic microscope images were taken to obtain a registration of the morphological effects of BPI on the embryos anatomy and to compare them to controls.

\subsection{1 | Statistical analysis}

The results obtained in this work were presented as the means \pm standard deviation. To determine the statistical differences, the data were evaluated with one-way ANOVA. Differences in $p<.05$ were considered statistically significant. Probit values were calculated using a probit table. The IC50 of each sample was calculated, using the probit value.

\section{3 | RESULTS AND DISCUSSION}

\section{1 | Nutritional composition of B. microphylla pulp and seeds fruit}

Table 1 shows the results of the berberis pulp proximate analysis. There is a lack of research studies that characterize B. microphylla nutritionally in the North Patagonia. Southern Chile fruits were
TABLE 1 Proximate composition of the fresh edible portion of $B$. microphylla fruit

\begin{tabular}{|c|c|c|}
\hline Parameters & Pulp & Seeds \\
\hline Moisture & $93.32 \pm 0.08^{a}$ & N.D \\
\hline Ash & $3.65 \pm 0.08^{a}$ & $2.21 \pm 0.01^{a}$ \\
\hline Protein & $1.33 \pm 0.09^{a}$ & $13.65 \pm 0.01^{a}$ \\
\hline Fat & $1.70 \pm 0.04^{a}$ & $18.90 \pm 0.65^{a}$ \\
\hline Available carbohydrates & $77.50 \pm 0.90^{b}$ & $65.24 \pm 1.14^{b}$ \\
\hline Total soluble sugar & $74.40 \pm 0.90^{b}$ & \\
\hline Total reducing sugar & $3.10 \pm 0.10^{b}$ & \\
\hline
\end{tabular}

Notes: Results are represented as mean \pm standard deviation $(n=3)$ of three independent experiments. $\mathrm{a}=(\mathrm{g} / 100 \mathrm{~g} \mathrm{FW}) . \mathrm{b}=(\mathrm{mg}$ equivalents of glucose/g FW).

analyzed by Ruiz et al. (2010). Our results compared to similar studies obtained previously, show no significant differences. The main nutrient found in pulp were sugars. The soluble-sugar content in pulp were $74.40 \pm 0.90 \mathrm{mg}$ glucose equivalents/g of $\mathrm{FW}$. Total reduced sugars were $3.10 \pm 0.10 \mathrm{mg}$ equivalents of glucose $/ \mathrm{g}$ $\mathrm{FW}$, which comprises up to $0.3 \%$. The glucose and fructose concentration in calafate have been described varying from $0.3 \%$ to $5 \%$ of fresh weight (Ruiz et al., 2010). Agronomic and ecological studies described that there is a strong relationship between the soluble sugar content and a possible tolerance to stress states. The plant metabolism is redirected toward synthesis of cryoprotectant molecules such as sugar (Boeri, Piñuel, Sharry, Tombari, \& Barrio, 2017; Rosa et al., 2009). The accumulation of carbohydrates biomolecules on Berberis buxifolia fruits relate to fruit quality characteristics such as texture, flavor and color (Arena, Zuleta, Dyner, Constenla, \& Curvetto, 2013). Table 1 shows the proximal analysis of berberies seeds. The studies about. B. microphylla are focused in the analysis of pulp components and there are only few studies of seeds berberies. The total content of carbohydrates is higher with a value of $65.24 \pm 1.14$ followed by the content of fat with values of $18.90 \pm 0.65$ and a higher content of protein with values of $13.65 \pm 0.01$. This value was higher when compared to the content of protein of pulp berberies (Table 1).

\section{2 | Extraction yield and total polyphenols content (TPC)}

The TPC extraction yield was of $38.60 \mathrm{~g}$ lyophilized EB/100 g fruit (DW). Ethanol is the most valued solvent in the extraction of possible antioxidant agents present in natural extracts. Ethanol has characteristics that make it the best option to develop nutritional supplements such as its low economic cost and its nontoxic effect. The TPC values determined by the $\mathrm{FC}$ method was in accordance to the ones reported by Mariangel, Reyes-Diaz, Lobos, Bensch, Schalchli, and Ibarra (2013) under the same extraction conditions. The result of this study was higher values when compared to the values described by Ruiz et al. (2014) in different berberis species with a TPC value of 
60.85 umoL GAE/g, FW. B. microphylla previous studies have shown that production of secondary metabolites depends on growth environmental conditions (Mariangel et al., 2013; Ruiz et al., 2010, 2014). Environmental and nutrient stresses have an impact on the phenolic compounds levels in plants and can affect the metabolic routes involved for the formation and accumulation of these compounds (Akula \& Ravishankar, 2011). B. microphylla fruits analyzed in this work, were collected from the Eastern Patagonia region with semi-arid climates. This could explain the TPC higher content determined in this work with respect to Ruiz et al. $(2010,2014)$ who used samples from hyper humid to humid climates (south of Chile). To be considered as a superfruit, TPC is expressed as mg GAE/100 g FW, with values between 113.02 and 1,620.00 mg GAE/100 g FW (Chang et al., 2019). Our results show that the calafate could be considered a superfruit due to a TPC of 1,035.03 mg GAE/100 g FW.

\section{3 | Determination of polyphenols components in B. microphylla pulp fruit}

The polyphenolic components of berberis fruits were analyzed using the HPLC-DAD method. In this study the content of EB anthocyanins was higher than the content of flavanols and flavon-3-ols (Table 2). The main anthocyanins identified were the group of 3glucoside conjugates, delphinidin-3-glucoside with a concentration of $23.61 \mu \mathrm{mol} / \mathrm{g}$, followed by petunidin-3-glucoside with a concentration of $7.70 \mu \mathrm{mol} / \mathrm{g}$ and Cyanidin 3- O-p-coumaroyl-glucoside with a concentration of $3.8 \mu \mathrm{mol} / \mathrm{g}$. The concentration of anthocyanins in berberis was $40 \mu \mathrm{mol} / \mathrm{g}$ of fresh weight, 1.5 times higher that values

TABLE 2 Quantification of phenolic compounds (nonanthocyanin and anthocyanin) in the hydroethanolic extracts of fruit by HPLC-DAD

\begin{tabular}{|lr|}
\hline Analyte & Concentration \\
\hline Non-anthocyanin phenolic compounds $(\mu \mathrm{g} / \mathrm{g}$ EE) & \\
\hline Gallic acid & $48.17 \pm 6.84$ \\
\hline OH-Tyrosol & $155.00 \pm 10.58$ \\
\hline Syringic acid & $368.55 \pm 4.41$ \\
\hline Caffeic acid & $1,134.54 \pm 77.06$ \\
\hline p-coumaric acid & $86.46 \pm 4.83$ \\
\hline trans-resveratrol & $5.08 \pm 0.76$ \\
\hline Quercetin-3-glucoside & $4.97 \pm 0.75$ \\
\hline Quercetin-3-galactoside & $5.87 \pm 0.88$ \\
\hline Quercetin & $1,092.75 \pm 25.25$ \\
\hline Anthocyanin phenolic compounds (mg/g EE) & \\
\hline Delphinidin 3- O-glucoside & $11.10 \pm 0.04$ \\
\hline Cyanidin 3- O-p-coumaroylglucoside & $2.23 \pm 0.11$ \\
\hline Petunidin 3- O-glucoside & $3.69 \pm 0.05$ \\
\hline Peonidin 3- O-glucoside & $0.69 \pm 0.04$ \\
\hline Malvidin 3-O-glucoside & $1.61 \pm 0.05$ \\
\hline
\end{tabular}

Note: Results are expressed as mean \pm standard deviation $(n=3)$. reported for this specie by Ulloa-Inostroza et al. (2017). The main anthocyanin family was the glucose derivatives of delphinidin, petunidin, and cyanidin components. Analysis of anthocyanidin components indicate that delphinidin-3-glucoside was the major anthocyanin of $B$. microphylla, with a percentage of $57.50 \%$ of total anthocyanins, 1.7 times higher than the percentage determined on "maqui" (Aristotelia chilensis) (Schreckinger, Lotton, Lila, \& De Mejía, 2010).

Nine non-anthocyanins components in fruits of berberis were identified and quantified (Table 2). A chromatogram of chromatographic profile of a sample is presented in Figure 2. The analyzed compounds were successfully separated and identified by comparing their elution times and chromatogram with standards used. Table 2 presents the concentration of individual non-anthocyanins. The most interesting result was the identification of caffeic acid and quercetin, showing a concentration of 6.30 and $3.60 \mu \mathrm{mol} / \mathrm{g}$ extract respectively. Caffeic acid and quercetin are the components that have been most identified and quantified in plant tissues. These polyphenols are present in many food sources, including blueberries. Currently, there is a high research interest in phenolic compounds for their biological properties such as the antioxidant activity, antibacterial activity, antiviral activity and anti-inflammatory activity. (Magnani, Isaac, Correa, \& Salgado, 2014; Wang et al., 2016). The quercetin molecule and its main derivatives have been reported as the most abundant flavonoid of calafate fruits. Many of the compounds identified by HPLC, were the same compounds determined by Ruiz et al. (2010) except for the caffeic acid. However, most of the concentrations obtained by these groups of research were low compared to the value determined in this work. Due to its potential health benefits of quercetin and caffeic acid, the calafate berry could be used as a nutraceutical ingredient in the food and pharmaceutical industries. To the best of our knowledge, this is the first report of two important compounds in terms of potential application of the fruit as a bioactive compounds source: trans-resveratrol and $\mathrm{OH}$-tyrosol. These compounds have been reported in different matrixes and have been associated to several health promoting effects. The $\mathrm{OH}$-tyrosol was found at similar levels than levels found in grape derived products such as wine. Its high antioxidant capacity has been described using in vitro models. Its eventual preventive capacity in certain pathologies has also been described. The results of the present study in could have a potential future use for these therapeutic purposes. With respect to trans-resveratrol, these levels were relatively low. However, the fact of being present could be helpful to understand possible interactions effects between the extracts phenolics composition and its antioxidant activity.

\section{4 | In vitro antioxidant activity}

Research on antioxidant activity may be a key issue in the medical and food industries due to the protection of ROS cells. Previous research has described the positive linear correlation between plant bioactive compounds with their antioxidant abilities (Karimi, Oskoueian, Hendra, Oskoueian, \& Jaafar, 2012). The antioxidant activity EB was calculated using the DPPH and ABTS assays. The results obtained 
(a)

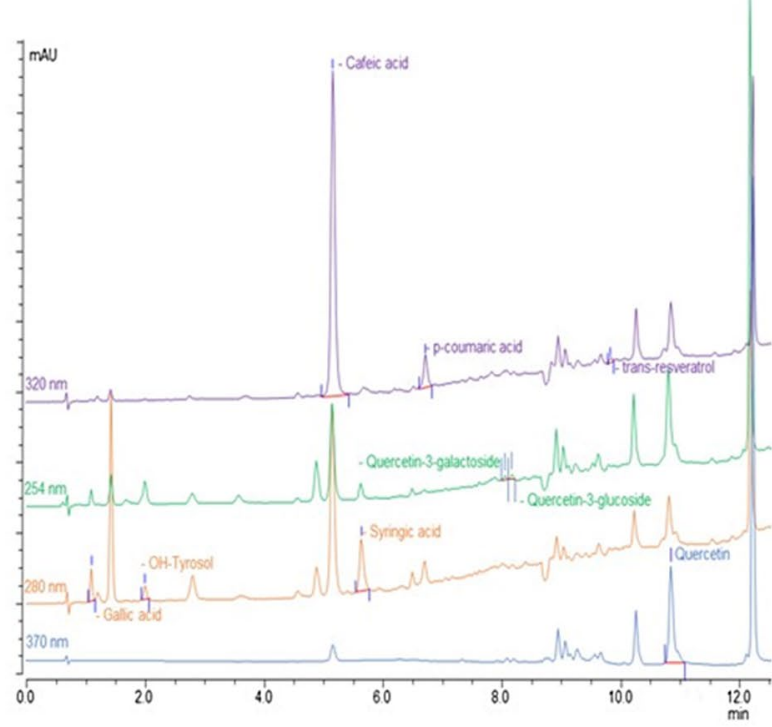

(b)

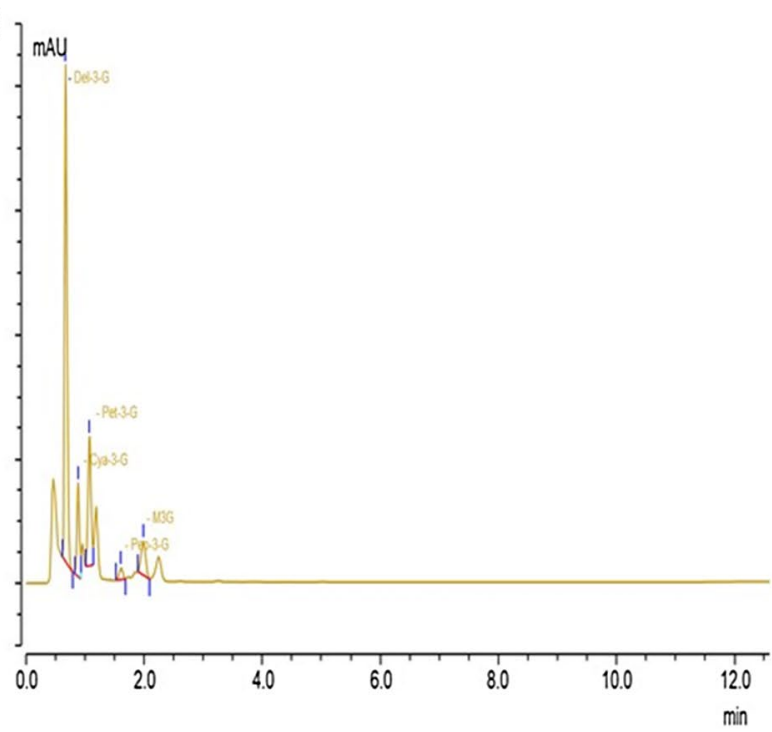

FIGURE 2 Chromatogram obtained for (a) Non-anthocyanin phenolic compounds and (b) Anthocyanin phenolic compounds quantified in this work

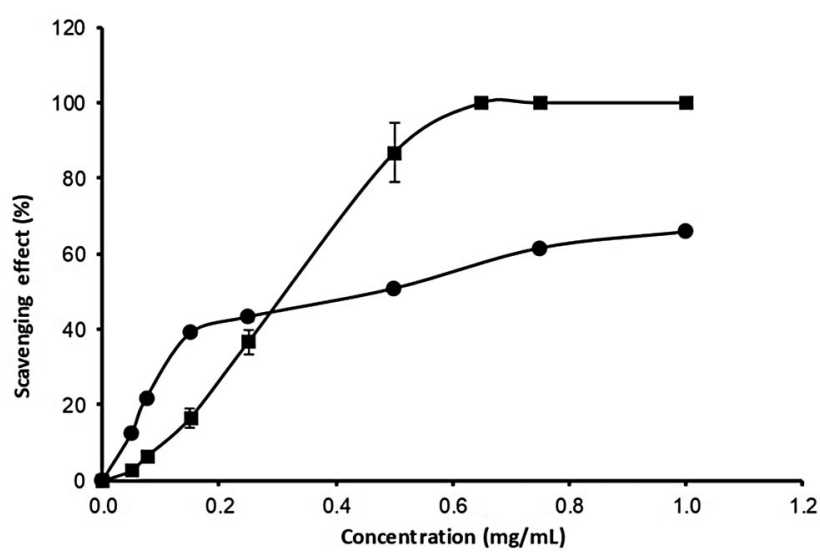

FIGURE 3 Scavenging effect on radicals ABTS+ ( $\bullet$ ) and DPPH $(\bullet)$ of EB lyophilized from B. microphylla at different concentrations $(0-1 \mathrm{mg} / \mathrm{ml})$. Bars represent the standard deviation of the mean

were $116.25 \pm 17.01$ and $137.8 \pm 1.90 \mu \mathrm{mol}$ TE/g FW respectively. These antioxidant activity values are in line with values reported by Ruiz et al. (2014). Calafate fruit antioxidant activity was around four times higher than the maqui berry, which is considered a superfruit for its high antioxidant activity (Genskowsky et al., 2016). EB was found to be effective in scavenging the ABTS and DPPH radical (Figure 3). The inhibition percentage of these radicals was concentration dependent. The IC50, concentration necessary to inhibit $50 \%$, using ABTS was of IC50 $=0.26 \mathrm{mg} / \mathrm{ml}$, and IC50 $=0.38 \mathrm{mg} / \mathrm{ml}$ when using the DPPH method. The scavenging of the $\mathrm{ABTS}^{+}$radical by the EB in this study was found to be as high as $100 \%$ up to a concentration of $0.65 \mathrm{mg} \mathrm{EB} / \mathrm{ml}$. However, the scavenging of the DPPH radical by EB was unable to get to $100 \%$ up to a concentration of $1 \mathrm{mg} \mathrm{EB} / \mathrm{ml}$. This shows that B. microphylla fruits extract presents a good ability to scavenge the ABTS radical.
The antioxidant tests used to evaluate the antioxidant activity of different molecules have different mechanisms of action. The tests can produce different trends of antioxidant activity. The ABTS antioxidant assay is generally indicated to evaluate the antioxidant activity of the hydrophilic compounds primarily. The DPPH antioxidant assay is used to analyze aqueous-organic extracts with hydrophilic and lipophilic compounds (Moo-Huchin et al., 2015). The ability of $B$. microphylla extracts to inhibit free radicals in different assays indicates that they could be useful as therapeutic agents to study pathological damage related to radicals.

\section{5 | Protective effect of polyphenols against AAPH-induced oxidative stress in the in vivo zebrafish embryo model}

In recent years, the interest in the evaluation of the antioxidant capacity of natural extracts is increasing due to the importance of ROS in the aging processes and its indication in different pathologies (Prior, 2003). Among the methods used to evaluate and quantify the generation of ROS at cellular level, we find the DCFH-DA fluorescent assay. This test was carried out with in vitro models (cell lines) and in vivo models (zebrafish). The exposure of free radical cells causes lipid oxidation and protein fragmentation (Peyrat-Maillard, Cuvelier, \& Berset, 2003). Zebrafish embryos were used to assess the reduction of oxidative stress induced by AAPH. The exposure and reduction of intracellular ROS was quantified by a decrease in green fluorescence. Figure 4a shows the zebrafish embryos after the DFCH-DA test. It was observed that the intensity of the fluorescence of 5 and $10 \mu \mathrm{g} \mathrm{EB} / \mathrm{ml}$ was lower when compared to the intensity of the group of embryos treated with AAPH. The nontreated group basal control presented the lowest fluorescence intensity. 

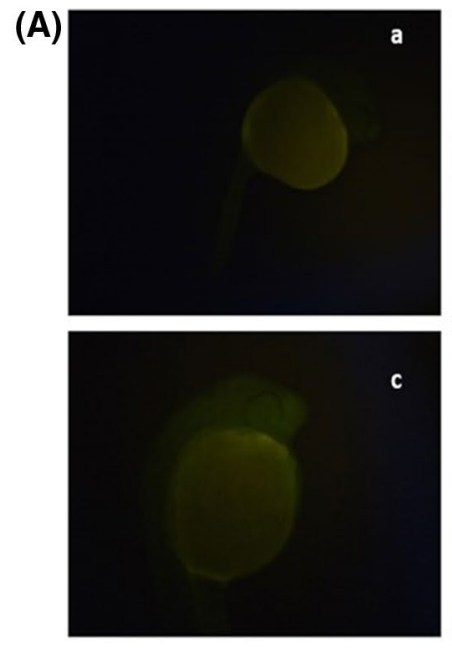

b
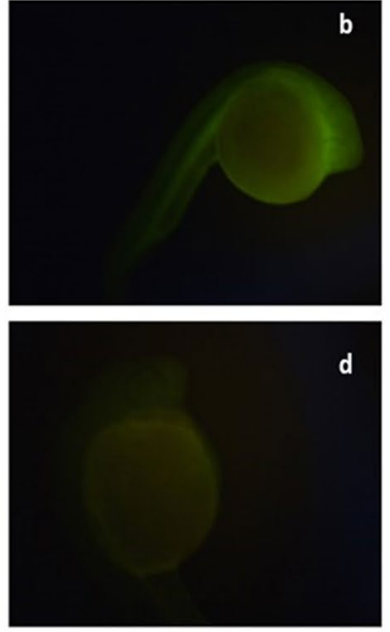

(B)

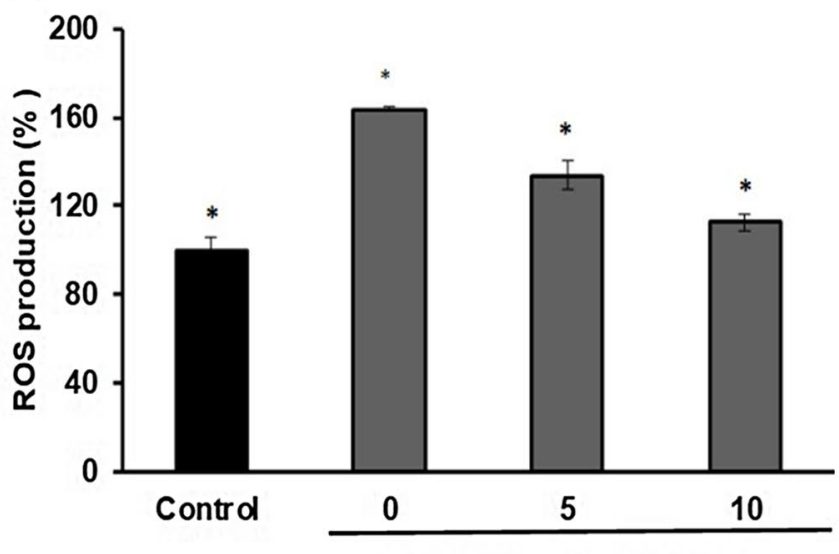

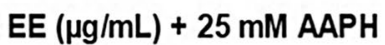

FIGURE 4 (A) Micrographs of reduction of ROS in zebrafish embryos of EB from B. microphylla (a) water (control without AAPH) (b) $25 \mathrm{mM}$ of AAPH (positive control), (c) $5 \mu \mathrm{g} \mathrm{EE} / \mathrm{ml}+25 \mathrm{mM} \mathrm{AAPH}$, and (d) $10 \mu \mathrm{g} \mathrm{EE} / \mathrm{ml}+25 \mathrm{mM}$ of AAPH ( $n=5$ ). (B) Protective effect of $\mathrm{EB}$ on $\mathrm{AAPH}$-treated reactive oxygen species (ROS) production in zebrafish. ROS levels were measured by Image J. Experiments were performed in triplicate and data are mean $\pm S D .{ }^{*} p<.05$

In the DCFH-DA test the fluorescence green intensity increases with ROS generation in the cells (Walker et al., 2012). In this study, the ROS level was $164 \%$ in AAPH-treated zebrafish compared to the control group (zebrafish treated with water). In contrast, zebrafish embryos treated with AAPH and EB at different concentrations (5 and $10 \mathrm{EE} \mu \mathrm{g} / \mathrm{ml}$ ) showed significantly reduced levels of ROS generation in cells. No significant differences with the control $(134 \%$ and $112 \%$ ) (Figure 4b) were observed. Natural extracts obtained of plants with antioxidant capacity have different compounds, which can function as antioxidants or exert synergistic effects between them (Dapkevicius, Venakutonis, van Beek, Linssen, 1998). The zebrafish model allowed detecting in vivo, the antioxidant properties of the calafate berberis fruits. Our results show that the $B$. microphylla fruits have excellent antioxidant properties evaluated using in vitro (ABTS/DPPH) and in vivo (zebrafish) models.

\subsection{Characterization of proteins from berberies seeds}

Studies on berberies fruits and its antioxidant activity have focused mainly on the identification and quantification of their polyphenol component and their relationship with antioxidant ability. Little has been studied about the protein components present in the fruit and their possible biological activities. This study has proposed the characterization of Calafate seed proteins and evaluation of their antioxidant capacity.

The BPI protein profiles and their gastro- duodenal digests were analyzed using the SDS-PAGE method. BPI present a simple profile of proteins with four abundant bands with molecular weights of 15, 24, 45 and $62 \mathrm{kDa}$ (Figure 5a). BPI was subject to simulation of gastric and duodenal digestion in vitro using pepsin and pancreatin respectively. Gastric digest of BPI present only two bands with molecular weight of 3 and $25 \mathrm{kDa}$. BPI duodenal digest present a protein profile of four bands with molecular weights of 3,12, 15 and $25 \mathrm{kDa}$ (Figure $5 \mathrm{~b}$ ). The bands of $3 \mathrm{kDa}$ correspond to small peptides produced during the hydrolysis process. The BPI cytotoxicity was tested in the zebrafish eggs in vivo model. BPI demonstrated a toxic effect for $50 \%$ of the zebrafish eggs in the concentration of $0.09 \mathrm{mg} /$ $\mathrm{ml}$ within the first $24 \mathrm{hpf}$ (Figure 6).

\section{7 | Antioxidant activity of proteins from berberies seeds}

$\mathrm{BPI}$, duodenal digest and fractions ( 3 and $10 \mathrm{kDa}$ ) were used to evaluate their antioxidant capacity by the ABTS and DPPH tests. BPI present a value of ABTS of $593.11 \pm 8.50 \mu \mathrm{mol} T E / g$. BPI duodenal digest present a value of $641.07 \pm 12.60 \mu \mathrm{mol} T E / g$ digests, the $3 \mathrm{kDa}$ fraction present a value of $45.92 \pm 2.60 \mu \mathrm{mol} \mathrm{TE} / \mathrm{g}$ fraction and the $10 \mathrm{kDa}$ fraction present a value of $361.02 \pm 20.30 \mu \mathrm{mol}$ $\mathrm{TE} / \mathrm{g}$ fraction. The IC50 value was evaluated for BPI and duodenal digest samples. It was found that BPI present a value of $2.95 \mathrm{mg} / \mathrm{ml}$ and duodenal digests present a value IC 50 of $0.80 \mathrm{mg} / \mathrm{ml}$. Duodenal digest present lower values than BPI. When the sample was evaluated using the DPPH method it was found that BPI present a value of $128.67 \pm 3.10 \mu \mathrm{mol} \mathrm{TE} / \mathrm{g} \mathrm{BPI}$ and duodenal digests present a value of $61.91 \pm 7.60 \mu \mathrm{moL} T E / g$ of digest. BPI present a value of IC50 of $16.50 \mathrm{mg} / \mathrm{ml}$ (Table 3). Protein isolates obtained from quinoa and amaranth have been described for their antioxidant capacity and their ability to inhibit lipid peroxidation in zebrafish. These protein isolates were hydrolyzed using pepsin and pancreatin. Their antioxidant capacity in vitro and in vivo was also demonstrated. (Vilcacundo et al., 2017, 2018). Piñuel, Boeri, et al. (2019) reported proteins isolate from white, black and red quinoa (Chenopodium quinoa Wild variety Real). Quinoa protein isolates (QPI) were obtained 
(a)

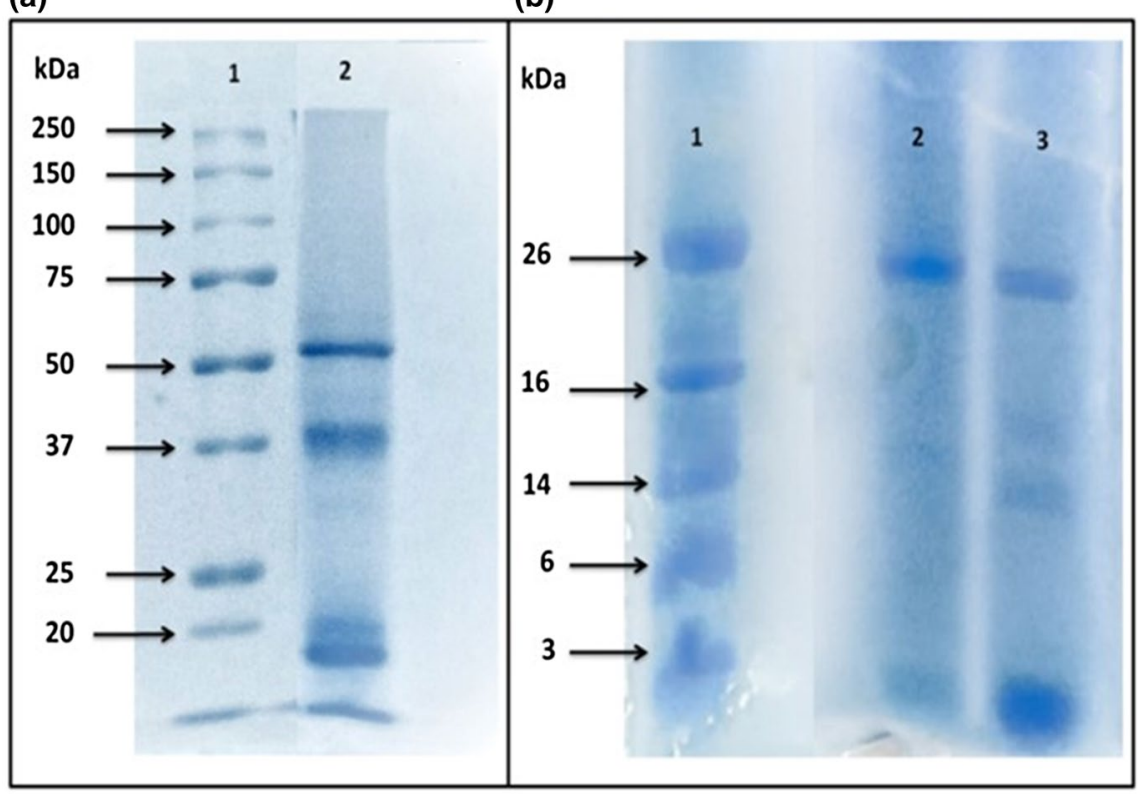
profile obtained by a 16\% Tricine-SDS-PAGE gel. Lane 1: molecular marker. Lane 2: gastric digestion. Lane 3: duodenal digestion

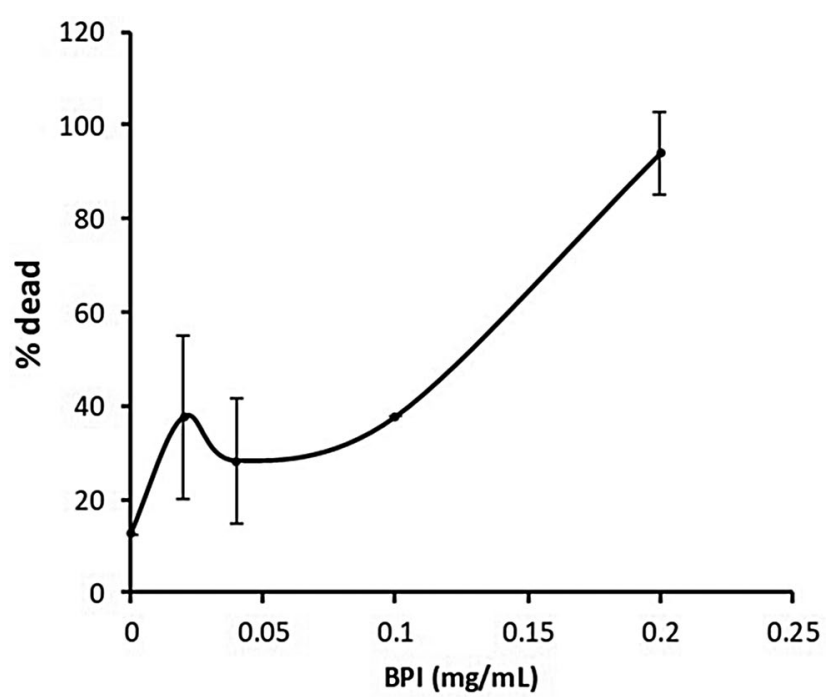

FIGURE 6 Cytotoxicity analysis of BPI in zebrafish eggs

for isoelectric precipitation from germinated quinoa. QPI underwent simulation gastro-intestinal model in vitro. The hydrolyzates present high antioxidant activity by the ORAC, DPPH and ABTS assays. Piñuel, Vilcacundo, et al. (2019) reported proteins with antioxidant activity obtained from the Phaseolus vulgaris variety Pinto. Protein concentrates present antioxidant activity by ORAC, DPPH and ABTS tests. Bean proteins present inhibition of peroxidation lipidic in the zebrafish model. The bean protein concentrate was hydrolyzed with pepsin and pancreatin enzymes. These hydrolyzates were fractionated by the ultrafiltration membrane technique. The fractions also presented antioxidant activity. For all the above, vegetable proteins obtained from different matrices can have antioxidant capacity. This activity can be evaluated using different analytical methods.
TABLE 3 Antioxidant activity of the BPI and duodenal digest determined by ABTS and DPPH

\begin{tabular}{|c|c|c|c|}
\hline & Sample & IC50 mg/ml & $\begin{array}{l}\text { Antioxidant } \\
\text { activity ( } \mu \mathrm{mol} \\
\text { TE/g) }\end{array}$ \\
\hline & ABTS & ABTS & DPPH \\
\hline BPI & $2.90^{b}$ & $593.11 \pm 8.50^{d}$ & $128.67 \pm 3.11^{b}$ \\
\hline DD & $0.74^{\mathrm{a}}$ & $641.07 \pm 12.60^{c}$ & $61.91 \pm 7.60^{b}$ \\
\hline $10 \mathrm{KDa}$ fraction & $n-d$ & $361.02 \pm 20.30^{b}$ & $19.50 \pm 8.32^{a}$ \\
\hline $3 \mathrm{KDa}$ fraction & $n-d$ & $45.92 \pm 2.60^{a}$ & $22.8 \pm 4.40^{a}$ \\
\hline
\end{tabular}

Note: Different letters indicate significant differences between the means of same column $(p<.05)$.

Food quality can be impaired by the accumulation of oxidative reactions that affect the taste, aroma, texture and color of the food. To avoid this, there must be a balance between oxidizing reactions and antioxidant factors (Ali, Ahsan, Zia, Siddiqui, \& Khan, 2020). The molecules that are involved in the oxidation reactions of food can be lipids and proteins molecules. In lipids, these reactions result in lipid peroxidation. During this process, carbonyl compounds are produced resulting in the rancid aroma of lipids. Carbonyls compounds can be associated with proteins and affect their functionality (Elias, Kellerby, \& Decker, 2008). However, it is known that many proteins have antioxidant capacity and can be used to inhibit oxidation reactions and lipid peroxidation. Blood proteins have from $10 \%$ to $50 \%$ ability to inhibit peroxyl radicals present in the blood plasma (Frei, Stocker, \& Ames, 1998). These proteins with antioxidant activity can be used to produce hydrolyzate using different methods such as enzymatic hydrolysis, fermentation and simulated gastrointestinal digestion (gastric and duodenal simulation). These hydrolyzates 
content small peptides with capacity to inhibit free radical and inhibit lipid peroxidation. Enzymatic hydrolysis is the most widely used method to produce hydrolyzates of proteins and bioactive peptides. Enzymatic hydrolysis of food proteins is generally recognized as an efficient, safe, fast and relatively inexpensive procedure for the biotechnology and food industry (Nwachukwu \& Aluko, 2019).

\section{4 | CONCLUSIONS}

Calafate berberis (B. microphylla) fruits cultivated in the arid Argentinian Patagonia region present anthocyanins high concentration with high antioxidant capacity. Anthocyanins components could be responsible for the EB antioxidant activity. The polyphenols compounds and their antioxidant activity increase berberis fruit value and quality. For the first time, the proteins present in seeds of Calafate berberis fruit were described. The proteins from seeds of B. microphylla and their gastric and duodenal digests present antioxidant activity. In the future, the proteins and peptides can be identified using the mass spectrometric analysis. The characterization of the components of Calafate fruit can increase the interest of the consumers and can be used as a functional ingredient or simply as an ingredient in foods supplements.

\section{ACKNOWLEDGMENT}

Thanks to Agencia de Promoción Científica for support with the project PICT-2015-1698. Thanks to BIOALI-CYTED for their support to scientific research.

\section{CONFLICT OF INTEREST}

The authors declare that they have no conflict of interests.

\section{ORCID}

Wilman Carrillo iD https://orcid.org/0000-0002-8517-0134

\section{REFERENCES}

Acosta, C., Carpio, C., Vilcacundo, R., \& Carrillo, W. (2016). Identification of proteins isolate from amaranth (Amaranthus caudatus) by sodium dodecyl sulfate-polyacrylamide gel electrophoresis with water and $\mathrm{NaCl} 0.1 \mathrm{M}$ solvents. Asian Journal of Pharmaceutical and Clinical Research, 9, 331-333.

Afrin, S., Giampieri, F., Gasparrini, M., Forbes-Hernandez, T. Y., VarelaLópez, A., Quiles, J. L., ... Battino, M. (2016). Chemopreventive and therapeutic effects of edible berries: A focus on colon cancer prevention and treatment. Molecules, 21, 169. https://doi.org/10.3390/ molecules21020169

Akula, R., \& Ravishankar, G. A. (2011). Influence of abiotic stress signals on secondary metabolites in plants. Plant Signaling and Behavior, 6, 1720-1731. https://doi.org/10.4161/psb.6.11.17613

Ali, S. S., Ahsan, H., Zia, M. K., Siddiqui, T., \& Khan, F. H. (2020). Understanding oxidants and antioxidants: Classical team with new players. Journal of Food Biochemistry, 44(3), e13145. https://doi. org/10.1111/jfbc.13145

Association of Official Analytical Chemists. (1990). Official methods of analysis (16th ed.). Arlington, VA: Author.

Arena, M. E., Postemsky, P. D., \& Curvetto, N. R. (2017). Changes in the phenolic compounds and antioxidant capacity of Berberis microphylla G. Forst. berries in relation to light intensity and fertilization.
Scientia Horticulturae, 218, 63-71. https://doi.org/10.1016/j.scien ta.2017.02.004

Arena, M. E., Zuleta, A., Dyner, L., Constenla, D., Ceci, L., \& Curvetto, N. (2013). Berberis buxifolia fruit growth and ripening: Evolution in carbohydrate and organic acid contents. Scientia Horticulturae, 158, 52-58. https://doi.org/10.1016/j.scienta.2013.04.026

Barboza, G. E., Cantero, J. J., Núñez, C., Ariza Espinar, L., \& Pacciaroni, A. D. V. (2009). Medicinal plants: A general review and a phytochemical and ethnopharmacological screening of the native Argentine Flora. Kurtziana, 34, 7-365.

Boeri, P. A., Piñuel, M. L., Sharry, S., Tombari, A., \& Barrio, D. A. (2017). Chemical and biological characterization from condalia microphylla fruits, a native species of Patagonia Argentina. Journal of Agricultural Science and Technology B, 7, 395-405. https://doi.org/10.17265/2161-6264/2017.06.004

Chang, S. K., Alasalvar, C., \& Shahidi, F. (2019). Superfruits: Phytochemicals, antioxidant efficacies, and health effects. A comprehensive review. Critical Reviews in Food Science and Nutrition, 59, 1580-1604. https://doi.org/10.1080/10408398.2017.1422111

Dapkevicius, A., Venakutonis, R., vanBeek, T. A., \& Linssen, J. P. H. (1998). Antioxidant activity of extracts obtained by different isolation procedures from some aromatic herbs grown in Lithuania. Journal of the Science of Food and Agriculture, 77, 140-146. https://doi.org/10.1002/ (SICI)1097-0010(199805)77:1<140:AID-JSFA18>3.0.CO;2-K

Elias, R. J., Kellerby, S. S., \& Decker, E. A. (2008). Antioxidant activity of proteins and peptides. Critical Reviews in Food Science and Nutrition, 48, 430-441. https://doi.org/10.1080/10408390701425615

Fontana, A., Antoniolli, A., Fernández, M., \& Bottini, R. (2017). Phenolics profiling of pomace extracts from different grape varieties cultivated in Argentina. RSC Advances, 7, 29446-29457. https://doi. org/10.1039/C7RA04681B

Frei, B., Stocker, R., \& Ames, B. N. (1988). Antioxidant defenses and lipid peroxidation in human blood plasma. Proceedings of the National Academy of Sciences of the United States of America, 85, 9748-9752. https://doi.org/10.1073/pnas.85.24.9748

Fuentes, L., Figueroa, C. R., Valdenegro, M., \& Vinet, R. (2019). Patagonian berries: Healthy potential and the path to becoming functional foods. Foods, 8, 289. https://doi.org/10.3390/foods8080289

Genskowsky, E., Puente, L. A., Pérez-Álvarez, J. A., Fernández-López, J., Muñoz, L. A., \& Viuda-Martos, M. (2016). Determination of polyphenolic profile, antioxidant activity and antibacterial properties of maqui [Aristotelia chilensis (Molina) Stuntz] a Chilean blackberry. Journal of the Science of Food and Agriculture, 96, 4235-4242.

Hu, Y. R., Ma, H., Zou, Z. Y., He, K., Xiao, Y. B., Wang, Y., ... Li, X. G. (2017). Activation of Akt and JNK/Nrf2/NQO1 pathway contributes to the protective effect of coptisine against $\mathrm{AAPH}$-induced oxidative stress. Biomedicine \& Pharmacotherapy, 85, 313-322.

Kampa, M., Nifli, A. P., Notas, G., \& Castanas, E. (2007). Polyphenols and cancer cell growth. In: S.G. Amara, E. Bamberg, B. Fleischmann, T. Gudermann, S.C. Hebert, R. Jahn, ... R. Zechner (Eds.), Reviews of physiology, biochemistry and pharmacology (Vol 159, 79-113). Berlin, Heidelberg: Springer.

Karimi, E., Oskoueian, E., Hendra, R., Oskoueian, A., \& Jaafar, H. Z. (2012). Phenolic compounds characterization and biological activities of Citrus aurantium bloom. Molecules, 17, 1203-1218. https://doi. org/10.3390/molecules17021203

Lanzi, C. R., Perdicaro, D. J., Antoniolli, A., Piccoli, P., Prieto, M. A. V., \& Fontana, A. (2018). Phenolic metabolites in plasma and tissues of rats fed with a grape pomace extract as assessed by liquid chromatography-tandem mass spectrometry. Archives of Biochemistry and Biophysics, 651, 28-33. https://doi.org/10.1016/j.abb.2018.05.021

Liu, Z., Ren, Z., Zhang, J., Chuang, C. C., Kandaswamy, E., Zhou, T., \& Zuo, L. (2018). Role of ROS and nutritional antioxidants in human diseases. Frontiers in Physiology, 9, 477.

López de Dicastillo, C., López-Carballo, G., Gavara, R., Muriel Galet, V., Guarda, A., \& Galotto, M. J. (2019). Improving polyphenolic thermal stability of Aristotelia Chilensis fruit extract by encapsulation within 
electrospun cyclodextrin capsules. Journal of Food Processing and Preservation, 43, e14044.

Magnani, C., Isaac, V. L. B., Correa, M. A., \& Salgado, H. R. N. (2014). Caffeic acid: A review of its potential use in medications and cosmetics. Analytical Methods, 6, 3203-3210.

Mariangel, E., Reyes-Diaz, M., Lobos, W., Bensch, E., Schalchli, H., \& Ibarra, P. (2013). The antioxidant properties of calafate (Berberis microphylla) fruits from four different locations in southern Chile. Ciencia e Investigación Agraria, 40, 161-170.

Moo-Huchin, V. M., Moo-Huchin, M. I., Estrada-León, R. J., CuevasGlory, L., Estrada-Mota, I. A., Ortiz-Vázquez, E., \& Sauri-Duch, E. (2015). Antioxidant compounds, antioxidant activity and phenolic content in peel from three tropical fruits from Yucatan, Mexico. Food Chemistry, 166, 17-22.

Nwachukwu, I. D., \& Aluko, R. E. (2019). Structural and functional properties of food protein-derived antioxidant peptides. Journal of Food Biochemistry, 43, e12761.

Pennington, J. A., \& Fisher, R. A. (2010). Food component profiles for fruit and vegetable subgroups. Journal of Food Compositions and Analysis, 23, 411-418.

Peyrat-Maillard, M. N., Cuvelier, M. E., \& Berset, C. (2003). Antioxidant activity of phenolic compounds in 2,20-azobis (2-amidinopropane) dihydrochloride (AAPH)-induced oxidation: Synergistic and antagonistic effects. Journal of the American Oil Chemists Society, 80 , 1007-1012.

Piñuel, L., Boeri, P., Zubillaga, F., Torreta, J., Barrio, D. A., Cruz, A., ... Carrillo, W. (2019). Production of White, Red and Black Quinoa (Chenopodium quinoa Willd Var. Real) protein isolates and its hydrolysates in germinated and non-germinated Quinoa samples and antioxidant activity evaluation. Plants, 8, 254.

Piñuel, L., Vilcacundo, E., Boeri, P., Barrio, D. A., Morales, D., Pinto, A., ... Carrillo, W. (2019). Extraction of protein concentrate from red bean (Phaseolus vulgaris L.): Antioxidant activity and inhibition of lipid peroxidation. Journal of Applied Pharmaceutical Science, 9, 45-58.

Prior, R. L. (2003). Fruits and vegetables in the prevention of cellular oxidative damage. American Journal of Clinical Nutrition, 78, 570S-578S.

Quinteros, M. F., Vilcacunco, R., Carpio, C., \& Carrillo, W. (2016). Isolation of proteins from sacha inchi (Plukenetia volubilis L.) in presence of water and salt. Asian Journal of Pharmaceutical and Clinical Research, 9, 193-196.

Ramirez, J. E., Zambrano, R., Sepúlveda, B., Kennelly, E. J., \& Simirgiotis, M. J. (2015). Anthocyanins and antioxidant capacities of six Chilean berries by HPLC-HR-ESI-ToF-MS. Food Chemistry, 176, 106-114.

Rosa, M., Prado, C., Podazza, G., Interdonato, R., González, J. A., Hilal, M., \& Prado, F. E. (2009). Soluble sugars: Metabolism, sensing and abiotic stress: A complex network in the life of plants. Plant Signaling and Behavior, 4, 388-393.

Rothwell, J. A., Urpi-Sarda, M., Boto-Ordoñez, M., Llorach, R., FarranCodina, A., Barupal, D. K., ... Scalbert, A. (2016). Systematic analysis of the polyphenol metabolome using the Phenol-Explorer database. Molecular Nutrition \& Food Research, 60, 203-211.

Roussos, P. A., Denaxa, N., \& Damvakaris, T. (2009). Strawberry fruit quality attributes after application of plant growth stimulating compounds. Scientia Horticulturae, 119, 138-146.

Ruiz, A., Hermosin-Gutierrez, I., Mardones, C., Vergara, C., Herlitz, E., Vega, M., ... vonBaer, D. (2010). Polyphenols and antioxidant activity of calafate (Berberis microphylla) fruits and other native berries from Southern Chile. Journal of Agriculture and Food Chemistry, 58, 6081-6089.

Ruiz, A., Mardones, C., Vergara, C., Hermosín-Gutiérrez, I., von Baer, D., Hinrichsen, P., ... Dominguez, E. (2013). Analysis of hydroxycinnamic acids derivatives in calafate (Berberis microphylla G. Forst) berries by liquid chromatography with photodiode array and mass spectrometry detection. Journal of Chromatography A, 1281, 38-45.

Ruiz, A., Zapata, M., Sabando, C., Bustamante, L., von Baer, D., Vergara, C., \& Mardones, C. (2014). Flavonols, alkaloids, and antioxidant capacity of edible wild Berberis species from Patagonia. Journal of Agriculture and Food Chemistry, 62, 12407-12417.

Schreckinger, M. E., Lotton, J., Lila, M. A., \& de Mejia, E. G. (2010). Berries from South America: A comprehensive review on chemistry, health potential, and commercialization. Journal of Medicinal Food, 13, 233-246.

Speisky, H., López-Alarcón, C., Gómez, M., Fuentes, J., \& SandovalAcuña, C. (2012). First web-based database on total phenolics and oxygen radical absorbance capacity (ORAC) of fruits produced and consumed within the south Andes region of South America. Journal of Agriculture and Food Chemistry, 60, 8851-8859. https://doi. org/10.1021/jf205167k

Ulloa-Inostroza, E. M., Ulloa-Inostroza, E. G., Alberdi, M., Peña-Sanhueza, D., González-Villagra, J., Jaakola, L., \& Reyes-Díaz, M. (2017). Native Chilean fruits and the effects of their functional compounds on human health. Superfood and Functional Food: An Overview of Their Processing and Utilization, 99-130.

Vilcacundo, R., Barrio, D., Carpio, C., García-Ruiz, A., Rúales, J., Hernández-Ledesma, B., \& Carrillo, W. (2017). Digestibility of quinoa (Chenopodium quinoa Willd.) protein concentrate and its potential to inhibit lipid peroxidation in the Zebrafish larvae model. Plant Foods for Human Nutrition, 72, 294-300. https://doi.org/10.1007/ s11130-017-0626-1

Vilcacundo, R., Barrio, D., Piñuel, L., Boeri, P., Tombari, A., Pinto, A., ... Carrillo, W. (2018). Inhibition of lipid peroxidation of kiwicha (Amaranthus caudatus) hydrolyzed protein using zebrafish larvae and embryos. Plants, 7, 69. https://doi.org/10.3390/plants7030069

Walker, S. L., Ariga, J., Mathias, J. R., Coothankandaswamy, V., Xie, X., Distel, M., ... Mumm, J. S. (2012). Automated reporter quantification in vivo: High-throughput screening method for reporter-based assays in zebrafish. PLoS ONE, 7, e29916. https://doi.org/10.1371/ journal.pone.0029916

Wang, Y., Zhu, J., Meng, X., Liu, S., Mu, J., \& Ning, C. (2016). Comparison of polyphenol, anthocyanin and antioxidant capacity in four varieties of Lonicera caerulea berry extracts. Food Chemistry, 197, 522-529. https://doi.org/10.1016/j.foodchem.2015.11.006

Yang, H. M., Ham, Y. M., Yoon, W. J., Roh, S. W., Jeon, Y. J., Oda, T., ... Kim, K. N. (2012). Quercitrin protects against ultraviolet B-induced cell death in vitro and in an in vivo zebrafish model. Journal of Photochemistry and Photobiology B: Biology, 114, 126-131. https:// doi.org/10.1016/j.jphotobiol.2012.05.020

How to cite this article: Boeri P, Piñuel L, Dalzotto D, et al. Argentine Patagonia barberry chemical composition and evaluation of its antioxidant capacity. J Food Biochem. 2020;00:e13254. https://doi.org/10.1111/jfbc.13254 